\title{
Introduction: Wildlife Crime
}

\author{
Stephen F. Pires ${ }^{1}$
}

Published online: 14 August 2015

(C) Springer Science+Business Media Dordrecht 2015

The poaching and the subsequent illegal trafficking of wildlife has become a booming local and global business (Alacs and Georges 2008) and is directly related to significant population losses for many species (Schneider 2012). In the last decade, countless media stories have been shared about the rise in poaching incidents particularly as they relate to the more photogenic animals, such as elephants, rhinos, and tigers. Many of these animals are critically endangered or have already gone extinct in the wild. For example, both the Western Black Rhino (Save the Rhino International 2015) and the Northern White Rhino are believed to be extinct in the wild (WWF 2015) as a direct consequence of rhino poaching for their horns. The poaching and illegal trafficking of animals and/or their by-products is not limited to only photogenic species. Pangolins, an insect-eating mammal that is similar to an armadillo, are not particularly attractive (Gill 2012) and do not receive much media attention, but are among the most poached mammals in the world for their meat and scales (Sutter 2014). The illegal wildlife trade is driven by a number of factors including the pet trade, accessories or luxury items, bush meat, and alternative medicines.

As a result of the increased attention to 'wildlife crime', researchers from a variety of disciplines have begun to give this problem more attention. One of those disciplines is criminology. In fact, many criminology-related publications on the topic have been published within the last couple of years. For instance, a quick search of Criminal Justice Abstracts using "wildlife conservation" produced 236 articles or books published from 1937 to 2005, and 247 articles and books in the ten years spanning 2006 to 2015. Clearly, criminologists have become more interested in the sub-discipline of wildlife crime, also known as 'conservation criminology', and have made great progress in explaining why it happens, how the trade operates and offer solutions to reduce its frequency.

The purpose of this special issue on "Wildlife Crime" is to create awareness of this global issue, increase dialogue with conservationists, and promote partnership research with park rangers and others on the ground. This special issue on wildlife crime covers a broad range of topics and includes conceptual and empirical papers.

Stephen F. Pires

sfpires@fiu.edu

1 Department of Criminal Justice, Florida International University, 11200 SW 8th Street, PCA-368A, Miami, FL 33199, USA 
The first article, a conceptual piece, "From CRAVED to CAPTURED: Introducing a Product-Based Framework to Examine Illegal Wildlife Markets" authored by William Moreto and Andrew Lemieux offers a new framework built on the CRAVED model. The CRAVED model, initially introduced by Ronald Clarke (1999), was created to understand theft variation of products. Specifically, products that were frequently stolen and sold in illicit markets would be those that are more concealable, removable, available, valuable, enjoyable, and disposable. In their first section, Moreto and Lemieux discuss the literature on wildlife crime and previous applications of the CRAVED model to traditional and wildlife hot products. In this discussion, they note that the CRAVED characteristics of wildlife products may vary depending on the stage of the trade (e.g., harvest, trafficking, processing, and sale to consumer) and this can ultimately explain variation in poaching. In the second section, Moreto and Lemieux explain that wildlife products differ from traditional inanimate hot products in three major ways. Processing, longevity (i.e., shelf-life), and temporary or final use of wildlife products vary between species and affects their demand by actors and consumers alike. These three factors are unaccounted for by the CRAVED model and this is a serious limitation that may explain theft variation of animal derived products. As a result, Moreto and Lemieux introduce the framework CAPTURED (concealable, available, processable, transferrable, useable, removable, enjoyable, desirable) to fully understand variation in wildlife products throughout the market continuum. In the final section of their article, they apply the CAPTURED model to a case study of elephant poaching for ivory to illustrate how certain concepts are relevant only at certain stages of the trade.

The second article, "A CRAVED Analysis of Multiple Illicit Parrot Markets in Peru and Bolivia" is written by myself, Stephen Pires, and is a continuation of my past research on the illegal parrot trade in Mexico (Pires and Clarke 2012) and in Bolivia (Pires and Clarke 2011). The present study examined multiple illicit markets in seven cities in two countries to test whether previous results are applicable to other neo-tropical illicit parrot markets. Secondary data consisting of market survey counts of parrots were used to test whether CRAVED concepts could explain why some parrot species are poached often while others are seldom poached or never at all. Like the results in previous studies, this study found just a few species in each city accounted for the great majority of poached parrots, otherwise known as the 80-20 rule. Further, most of the CRAVED concepts related to opportunity were significantly related to poaching variation. Specifically, accessible (i.e., range within 150 miles of a market), abundance (i.e., how common), and concealable (i.e., legally trappable species with quotas) were positively related to poaching counts, while removable (i.e., nest access) had no relationship. Of the demand-side concepts, only the measure of disposability (i.e., consumer demand) was significantly related to poaching, while valuable (i.e., market price) and enjoyable (i.e., attractiveness composite variable) were found unrelated. As a result of most parrots emanating from a local area around open-air illicit markets, it can be inferred that such markets incentivize poaching at the local level. To reduce parrot poaching and the larger illegal trade, open-air markets should be shut down in cities to dissuade individuals from poaching and trafficking. Further, local and national governments should incentivize development of eco-tourist businesses that can profit from parrot sightings and encourage locals to abstain from poaching.

In the third article, Gohar Petrossian, Nerea Marteache, and Julie Viollaz investigated "Where do Undocumented Fish Land? An Empirical Assessment of Port Characteristics for IUU Fishing". Illegal, unreported, and unregulated (IUU) fishing is a serious problem that affects fish stocks and the fishing communities that depend on them for survival. Ports of 
convenience (POC) enable illicit fishing by allowing "IUU fishing vessels to launder their catch into legal fish markets." The characteristics that make POCs attractive facilities to offload illicit fish catch has not been examined in previous work and is, thus, the objective of this study. Using a risky facilities framework (Eck, Clarke, and Guerette 2007), Petrossian, Marteache, and Viollaz examined port- and country-level characteristics of 94 global ports that were visited infrequently by IUU fishing vessels and compared them to 26 global ports that were frequently visited by IUU fishing vessels. Ports that were visited frequently by IUU vessels were significantly larger and experienced more vessel traffic. However, such ports also inspected a higher proportion of vessels, which was unanticipated by the authors'. At the country-level, IUU fishing vessels frequently visited ports in countries where illegal fishing is more prevalent, were less effective in inspecting fisheries, and more corrupt. A number of recommendations are made that can "disrupt the market of illegally caught fish" which enables IUU fishing in areas surrounding POCs.

Finally, Anita Lavorgna contributed, "The Social Organization of Pet Trafficking in Cyberspace." Markets for illicit goods, such as pet trafficking, have increasingly been present in cyberspace largely because cyberspace provides ease and anonymity. Yet, little is known on the topic of internet-facilitated pet trafficking. Lavorga uses a socioorganizational approach to examine how offenders are organized in internet-facilitated pet trafficking along with their modus operandi. Using case studies found in the Italian media, interviews with law enforcement experts, and conducting observational research of individuals selling illicit pets on hotspot websites and forums, Lavorgna develops a "four-fold typology in order to categorize the social actors involved." Results show that many individuals involved in the trade are not in highly structured organizations and relationships among offenders are often based on convenience. Techniques used by offenders to lure buyers into a sale include, but are not limited to, advertising with extremely low prices and encouraging buyers to buy pets that are "docile, well-trained, and suitable for amateurs and children." Considering that law enforcement is illequipped to combat cybercrimes like pet trafficking, the implications of Lavorgna's research are three-fold. First, law enforcement efforts should focus their efforts on hotspot websites for pet trafficking and share information with other agencies to aid investigations. Second, e-commerce companies that facilitate such trade should selfpolice to eradicate criminal markets. For example, EBAY has already signed an agreement to thwart pet trafficking in Italy. Finally, online participants within forums where pet trafficking peddlers are commonplace should report such activity.

The four articles in this special issue cover a wide range of topics, species, methods, and geographic locations. The articles were conceptual and empirical providing insight on the topic of wildlife crimes in the form of a new model and typology, and utilizing previous criminological frameworks to understand poaching variation and why certain ports attract illicit fish. It has been a great pleasure to be guest editor for this special issue on Wildlife Crime and it is my hope that this collection of work leads to further research in the field and encourages more criminologists to join the fold.

\section{References}

Alacs, E., \& Georges, A. (2008). Wildlife across our borders: A review of the illegal trade in Australia. Australian Journal of Forensic Sciences, 40(2), 147-160. 
Clarke, R. V. (1999). Hot products. Understanding, Anticipating and Reducing Demand for Stolen Goods. London: Home Office. Police Research Series, Paper, 112.

Eck, J. E., Clarke, R. V., \& Guerette, R. T. (2007). Risky facilities: Crime concentration in homogeneous sets of establishments and facilities. Crime Prevention Studies, 21, 225.

Gill, V. (2012). Are these animals too 'ugly' to be saved? BBC Magazine. Retrieved from: http://www.bbc.com/ news/magazine-20323753.

Pires, S. F., \& Clarke, R. V. (2011). Sequential foraging, itinerant fences and parrot poaching in Bolivia. British Journal of Criminology, 51, 314-335.

Pires, S., \& Clarke, R. V. (2012). Are parrots CRAVED? An analysis of parrot poaching in Mexico. Journal of Research in Crime and Delinquency, 49(1), 122-146.

Save the Rhino International (2015). Poaching: The statistics. Retrieved from: https://www.savetherhino.org/ rhino_info/poaching_statistics.

Schneider, J. L. (2012). Sold into extinction: The global trade in endangered species. ABC-CLIO.

Sutter, J. (2014). The most trafficked mammal you've never heard of. CNN. Retrieved from: http://www.cnn. com/interactive/2014/04/opinion/sutter-change-the-list-pangolin-trafficking/.

WWF (2015). Species: Rhino overview. Retrieved from: http://www.worldwildlife.org/species/rhino. 